\title{
Cerebral Cystic Echinococcosis in the Light of Our Experience
}

\section{Klinik Deneyimlerimiz Işı̆̆ında Serebral Kistik Ekinokokkoz}

\author{
Yusuf Kurtuluş Duransoy, Mesut Mete, Mehmet Selçuki
}

Celal Bayar Üniversitesi Tıp Fakültesi, Nöroşirürji Anabilim Dalı, Manisa, Türkiye

\section{ÖZET}

Serebral kistik ekinokokkoz (SKE) nadir görülmekte, olup tüm kistik ekinokokkoz (kist hidatik) olgularının \%1-2'sini oluşturur. Lezyonlar genellikle tektir ve en sık supratentoryal bölgede yerleşir. Primer ve sekonder olarak ikiye ayrılan SKE'nin daha sık olarak görülen primer tipine, vücudun filtre sistemlerinden kaçan embriyolar yol açar; soliter ve fertil özellikler gösterir. Daha nadir olarak görülen sekonder tip ise ana kistin rüptürü sonucu skolekslerin embolizasyonu yoluyla meydana gelir, genellikle multipl ve infertildir. Kistlerin büyümesi yavaş olduğundan yakınma ve bulguların gelişimi geç olmaktadır. SKE kliniğinde baş ağrısı ve kusma en sık görülen başlangıç yakınmalarıdır. Nörolojik bulgular genellikle kafaiçi basınç artışına bağı ve kistin yerleşim yeri ile ilgili olarak gelişmektedir. Tanı klinik ve laboratuar bulgularının birlikte değerlendirilmesiyle konulur. Bilgisayarlı tomografi ve manyetik rezonans görüntüleme yöntemleri tek tek veya birlikte SKE tanısını koymada oldukça başarılıdır. Kistler bilgisayarlı tomografi ve manyetik rezonans görüntülemede iyi sınıllı, ince duvarlı, yuvarlak, homojen yapıda görülürler. En uygun tedavi yöntemi kistin cerrahi olarak Dowling tekniği ile doğurtularak patlatılmadan çıkartılmasıdır. Ancak doğurtulmasının mümkün olmadığı yerlerde ponksiyon yapılarak kist içeriğinin boşaltılması sonrası total çıkarım yapılabilir. Büyük kistlerin çıkarımı sonrasında erken dönemde porensefalik kist, subdural kanama gibi bir takım komplikasyonlar gelişebilir. (Turkiye Parazitol Derg 2013; 37: 277-81)

Anahtar Sözcükler: Serebral kistik ekinokokkoz, kist hidatik, intraventriküler, multipl, cerrahi tedavi

Geliş Tarihi: 31.01 .2013

Kabul Tarihi: 21.10.2013

\begin{abstract}
Cerebral cystic echinococcosis (CCE) is rare and constitutes 1-2\% of all cystic echinococcosis. The cysts are usually solitary and most frequently located in the supratentorial region. CCE is classified as primary and secondary. The primary cysts developed from the embryos which escaped from the filter systems are more frequent and usually solitary and fertile. The secondary cysts result from spontaneous, traumatic or surgical rupture of the primary CCE by embolization of scolices. They are usually multiple and infertile and do not have brood capsule or scolices. Symptoms usually develop slowly and are usually due to increased intracranial pressure and depend on the location of the cyst. Diagnosis is made by evaluation of both clinical and laboratory findings. Computed tomography and magnetic resonance imaging is successful in the diagnosis. The cysts are observed as spherical, well defined, with thin regular margins by these methods. The most appropriate treatment method is total surgical removal of the cyst without rupture by using Dowling's method. However, when it is not possible to remove without rupture, the cyst should be removed totally after puncture and aspiration of contents of the cyst. After removal of large cysts, complications such as porencephalic cysts and subdural hemorrhage can occur postoperatively. (Turkiye Parazitol Derg 2013; 37: 277-81)
\end{abstract}

Key Words: Cerebral cystic echinococcosis, hydatid cyst, intraventriculary, multiple, surgical treatment

Received: 31.01.2013

Accepted: 21.10 .2013

Bu çalışma Manisa Celal Bayar Üniversitesi'nde düzenlenen "Kistik Ekinokokkoz Sempozyumu"nda "Kistik Ekinokokkoz Kliniği ve Olgu Sunumları" oturumunda sunulmuştur, 17-18 Mayıs 2012, Manisa, Türkiye.

This study was presented at Cystic Echinococcosis symposium in Manisa University, Bu çalışma 17-18 May, 2012, Manisa, Turkey. Yazışma Adresi / Address for Correspondence: Dr. Yusuf Kurtuluş Duransoy, Celal Bayar Üniversitesi Tıp Fakültesi, Nöroşirürji Anabilim Dalı, Manisa, Türkiye. Tel: +90236233 3396 E-posta: ykduransoy@hotmail.com

doi:10.5152/tpd.2013.3078 


\section{GiRiş}

Echinococcus granulosus'un larva şeklinin yol açtığı kistik ekinokokkoz (KE) enfeksiyonu Türkiye'de insanlarda endemiktir. Kesin konağı köpek, asıl ara konağı ise koyun olan enfeksiyon insanlarda daha nadir ve rastlantısaldır (1-6). Hastalık insanlara, enfekte köpek dışkısıyla birlikte atılan parazitin gebe halkalarının parçalanmasıyla açığa çıkan yumurtaların, iyi yıkanmamış çiğ sebze ve meyvelerle, enfekte sularla, toprak veya köpekle temas sonrası eller aracılığı ile ağız yoluyla alınmasıyla bulaşır. Midede sindirime uğrayan yumurtalardan salınan embriyolar bağırsaktan kana karışarak vena porta aracılığıyla karaciğere ulaşır. Karaciğer hastalığın en çok görüldüğü primer organdır. Bir kısmı ise sistemik dolaşıma katılarak dalak ve akciğere ulaşıp bu organlarda da hidatik kistlere neden olabilir $(7,8)$. Serebral kistik ekinokokkoz (SKE) nadir olup tüm KE olgularının \%1-2'sinde rapor edilmiştir (7-9). Etkilenen hastaların \%80'i pediatrik yaş grubundandır $(7,9)$. Çocuklarda bu kadar sık görülmesi patent ductus arteriosus nedeniyle olabilir (7). SKE sıklıkla tek, yuvarlak ve uniloküler görünümdedir. En sık tutulum yeri supratentoryal bölge ve paryetal lobtur (1,9). Literatürde intraventriküler yerleşim gösteren az sayıda olgu bildirilmiştir $(1,7,10,11)$

Serebral kistler genellikle yavaş büyür (12), büyüme hızı 1-12 cm/yıl arasında değişebilir (13-18). Evliyaoğlu ve ark. (13) tekrarlayan beyin tomografileri sonucunda büyüme hızını $1 \mathrm{~cm} /$ ay olarak belirtirken, Kemaloglu ve ark. (14) 6 ayda 4,5 cm büyüme hızı bildirmişlerdir. Vaquero ve ark (15) $1 \mathrm{~cm} / \mathrm{yll}$, Kalelioğlu (16) ve ark. $5 \mathrm{~cm} / \mathrm{yıl}$, Sierra ve ark. (17) $5 \mathrm{~cm} / \mathrm{yıl}$ ve Pasaoglu ve ark. (18) $10 \mathrm{~cm} / \mathrm{yıl}$ oranında büyüme hızı bildirmişlerdir. Hastalarımızın birinde 7 ay önceki beyin manyetik rezonans görüntülemesinde (MRG) kist görünümü olmamasına rağmen yeni MRG'sinde en büyüğü $5 \mathrm{~cm}$ çapında toplam 4 adet kist saptadık (Resim 1). Bu olgumuzdaki SKE büyüme hızını tahminen $5 \mathrm{~cm} / 7$ ay olarak değerlendirdik.

SKE genellikle tektir, ancak az da olsa multipl kistli olgular bildirilmiştir. Özkan ve ark. (2) 25 adet, Yurt ve ark. (19) ise 24 adet serebral kistini cerrahi olarak çıkardıkları olgularını bildirmişlerdir. Çavuşoğlu ve ark. (20) 16 yaşında bir erkek çocukta 19 adet intrakranial kistini cerrahi olarak çıkardıkları bir olguyu sunmuşlardır. Duishanbai ve ark. (3), opere ettikleri 97 SKE olgusundan $11^{\prime}$ inin çoğul kistlere sahip olduğunu bildirmişlerdir. SKE kistleri primer ve sekonder olarak sınıflanabilir. Primer kistler; başka organ tutulumu olmaksızın larvanın direkt beyni tutması ile ortaya çıkar ve sıklıkla tektir. Skoleks ve yavru kapsüller içeren kistlerin rüptürü nükslere neden olabilir. Sekonder kistler ise primer kistlerin spontan, travmatik veya cerrahi rüptürüne bağlı olarak ortaya çıkar ve genellikle multipldir. Bunlar, skoleks ve yavru kapsül içermediğinden infertildirler $(7,20)$. Tek bir serebral lezyonu olan hastalarımızın biri primer tipe örnektir. Bu hastamızda yaptığımız tetkiklerde başka bir odak saptayamadık. Olgularımızdan bir diğerinde ise multipl serebral kistlere ek olarak ekokardiyografisinde ve kardiyak MRG'sinde sağ atriumda kistik lezyon saptadık. Bu hastamızın öncelikli olarak serebral kistlerini çıkarttık ve kardiyak kist için ilgili bölüme gönderdik ve ilgili bölümde kardiak kist cerrahi olarak boşaltıldı.

Serebral yerleşim en sık orta serebral arterin sulama alanına uyan paryetal lobtur $(9,10,12,21,22)$. Kafatası, kavernöz sinüs, göz küresi, pons, serebellum, ventrikül içi ve interpedinküler sistern-

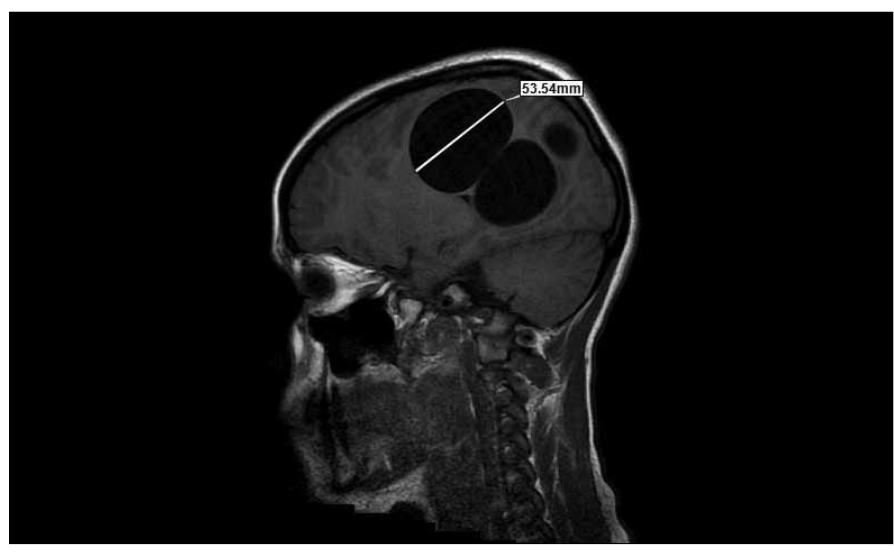

Resim 1. Yedi ay önceki MRG tetkikinde kist görünmeyen hastamızın yeni MRG'sindeki kist boyutu izlenmekte MRG: manyetik rezonans görüntüleme

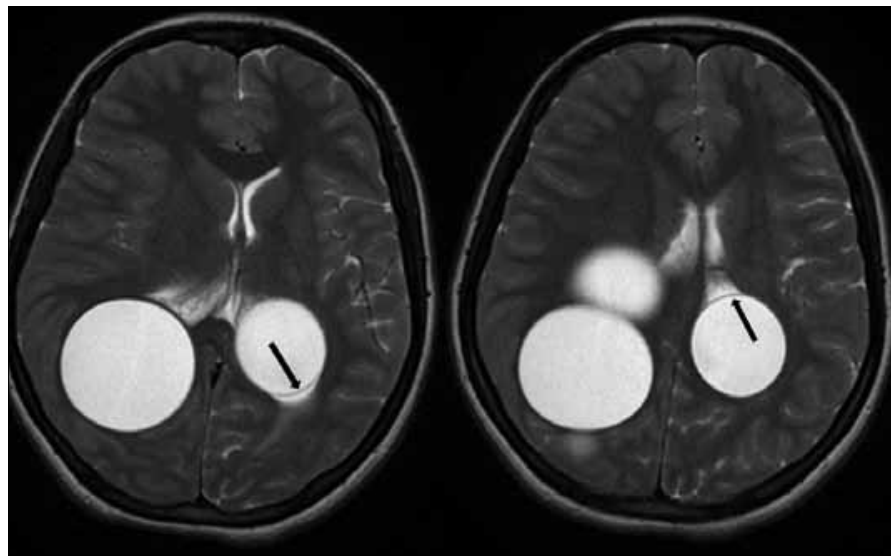

Resim 2. Multiple SKE olan hastamızın kraniyal MRG'sinde intraventriküler yerleşim gösteren kist görülmekte (siyah oklar ventrikül ile kist arasındaki kist duvarını göstermekte) SKE: serebral kistik ekinokokkoz

ler diğer yerleşim alanlarıdır $(7,23)$. Intraventriküler yerleşim çok daha nadir olup literatürde çok az sayıda olgu sunumları ve geniş seriler içinde bildirilen az sayıda olgular vardır $(1,7,10,11)$. Hastalarımızdan birinde toplam 4 adet kist vardı ve bu kistlerden biri intraventriküler yerleşimliydi (Resim 2).

Baş ağrısı ve kusma en sık başlangıç şikayetleri olup $(3,9,20,21,24)$, papil ödemi tanı anında çoğunlukla mevcuttur $(2,9,21)$ ve genellikle bilateraldir (24). Ekstremitelerde güçsüzlük, görme bozukluğu, ataksi, epileptik nöbet, gaita inkontinansı gibi şikayetler kistin yerleşim yerine bağlı olarak görülebilir (2, 3, 9). SKE'nin büyümesi yavaş olduğundan semptomların gelişimi de yavaştır ve nörolojik defisitler genellikle intrakranial basınç artışına bağlı olarak geç dönemde görülmektedir $(2,24)$. Literatürde çok nadir de olsa serebral herniasyon kliniği ile başvuran ve acil opere edilen olgular da mevcuttur $(20,25)$. Biz de epileptik nöbet ve bilinç kaybı sonrası serebral herniasyon kliniği ile başvuran bir hastamızı acil opere etmek zorunda kaldık. Bu hastamızda ameliyat öncesinde sadece beyin BT tetkiki ile SKE tanısı düşünerek operasyonu planlı yaptık ve kisti patlatmadan Dowling yöntemi ile doğurtarak çıkarttık.

Cerrahi planlama ve prognoz açısından preoperatif tanı önemlidir $(1,8)$. SKE'nin tanı ve ayırıcı tanısında ayrıca postoperatif takibinde 


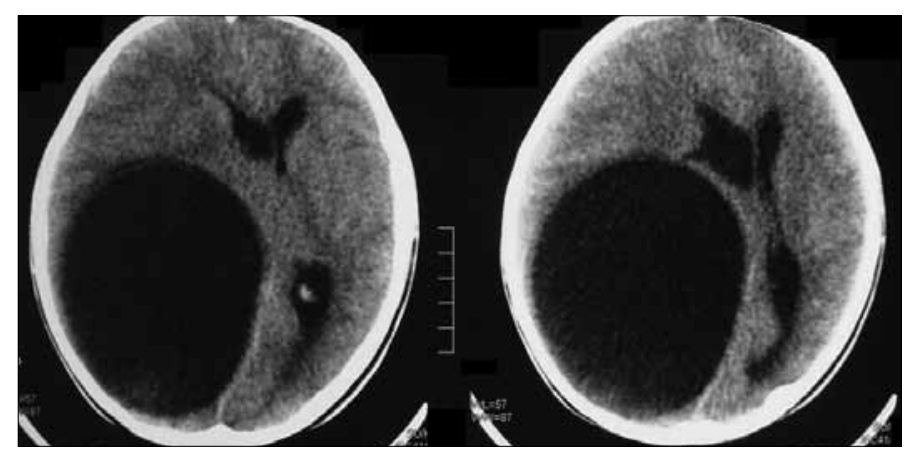

Resim 3. Bir hastamızın beyin BT'sinde soliter, düzgün sınırlı, yuvarlak, BOS ile aynı dansitede, homojen kistik lezyon görülmekte

BT: bilgisayarlı tomografi

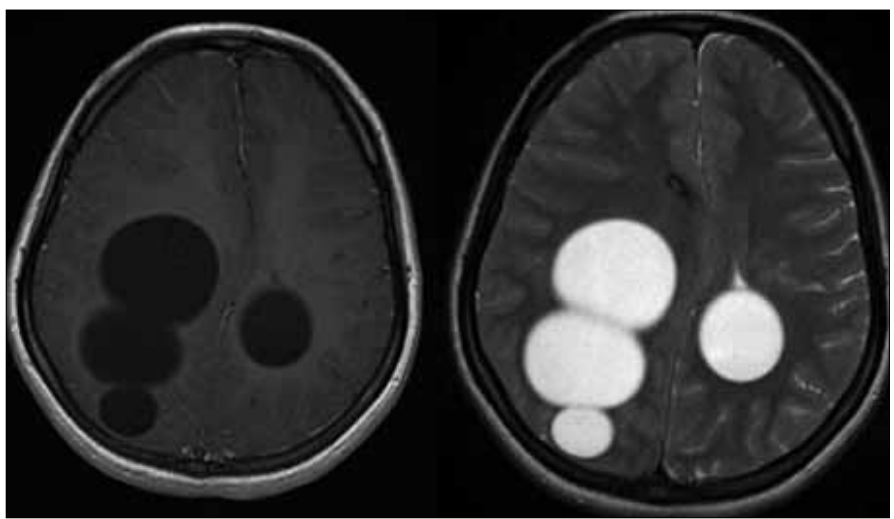

Resim 4. Bir hastamızın T1 ve T2 intensiteli MRG'sinde 4 adet SKE görülmekte

SKE: serebral kistik ekinokokkoz; MRG: manyetik rezonans görüntüleme

serolojik ve immünolojik testler önemlidir, fakat Duishanbai ve ark. SKE' de serolojinin özellikle karaciğer tutulumunun da olduğu multipl organ tutuluşlarında olduğu kadar değerli olmadığını bildirmişlerdir. Aynı çalışmada yazarlar bu serilerindeki soliter SKE'li olgularda serolojik çalışmaların negatif sonuçlandığını belirtmişlerdir (3). Tanı klinik, laboratuar ve görüntüleme yöntemleriyle konur. Seroloji yanında bilgisayarlı tomografi (BT) ve MRG tanıda oldukça önemlidir. Beyin BT ve MRG tek başına veya birlikte SKE tanısı koymada oldukça başarılı olup preoperatif dönemde kistin özelliği ve tedavi açısından iyi bir yol göstericidir. Kistler beyin BT ve MRG'de iyi sınırlı, ince duvarlı, yuvarlak genellikle homojen lezyonlar şeklinde görülürler (1, 3, 21-24, 26). Beyin BT'sinde perilezyonel ödem içermeyen beyin omurilik sıvısı (BOS) ile aynı dansitede kistik bir lezyon şeklinde olup (1, 3, 21, 23), kist duvarında kalsifikasyon saptanabilir (1, 9, 21, 22, 23, 27). Kist çevresinde nadiren ödem görülebilir (21, 22, 27). MRG'de kist sıvısı T1 ve T2 ağırlıklı imajlarda BOS ile izointens görünüme sahip olup, kist duvarı hem T1 hem de T2 ağırlıklı imajlarda düşük sinyal intensiteli halka şeklinde görülür $(3,21,22,27)$. SKE'nin ayırıc tanısında; araknoid kist, porensefalik kist, kistik tümörler ve apse düşünülmelidir (3, 21, 22, 27). SKE, kistik tümörler ve apseden kontrast tutan bir cidarın olmayışı ve mural nodül içermemesi ile ayırt edilirken, araknoid kist ve porensefalik kist genellikle sferik şekilli değillerdir $(9,21,22)$. SKE lezyonları solid, semisolid veya multiloküler kistik kitle şeklinde olup intravenöz kontrast madde sonrası kistteki rim kontrast

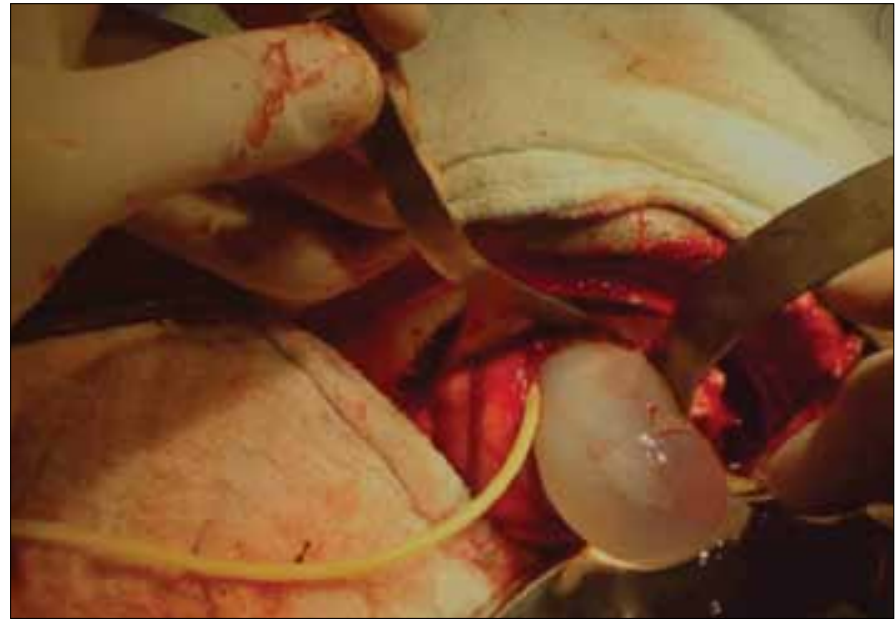

Resim 5. Bir hastamızdaki SKE Dowling yöntemi ile patlatılmadan doğurtulmakta

SKE: serebral kistik ekinokokkoz

madde tutulumu göstermez $(21,22)$. Kız veziküllerin görülmesi patognomoniktir ancak çok nadirdir (21). Bir hastamızda acil operasyon endikasyonu vardı ve MRG için zamanımız olmadığından sadece beyin BT çektirebildik. Beyin BT'sinde düzgün sınırlı, yuvarlak, BOS ile aynı dansitede, homojen kistik lezyon saptadık (Resim 3). Başka bir hastamızın beyin BT ve MRG'sinde düzgün sınırlı, yuvarlak, homojen, BOS ile aynı dansite ve intensitede kistik lezyonlar saptadık (Resim 4).

SKE tedavisinde medikal ve cerrahi tedavi eş zamanlı olmalıdır $(3,7,9,12)$. Literatürde albendazol tedavisi ile $(10 \mathrm{mg} / \mathrm{kg}$ günde 3 doz) tamamen kaybolan izole vakalar bildirilmiştir. Golematis ve ark. albendazol tedavisi ile büyük kistlerin küçüldüğünü, küçük kistlerin kaybolduğunu bildirirken (7), Erşahin ve ark. (9) medikal tedavinin, tekrarlayan ve ameliyat sırasında rüptüre olan hastalarda daha etkin olduğunu bildirmişlerdir. Kistin drenajı, kist sıvısının boşaltılıp germinal tabakasının çıkarılması ve kistin ağızlaştırılması gibi birçok cerrahi yöntem kullanılmışsa da en küratif cerrahi yöntem kistin patlatılmadan Dowling yöntemiyle doğurtulması ve ameliyat boşluğunun hipertonik sodyum klorürle yıkanmasıdır. Kist rüptüre olduğu takdirde anaflaktik şok, kimyasal menenjit ve kistin nüksü görülebilir $(1,3)$. Hastalığın rekürrens oranı \%19, perioperatif mortalite oranı \%8,48, mortalite oranı \%10-12 ve morbidite oranı \%9,8 olarak bildirilmiştir (12). Nadir de olsa postoperatif dönemde subdural higroma ve porensefalik kist görülebilen komplikasyonlar arasında sayılabilir $(2,3,9,12)$. Tüm hastalarımızdaki hidatik kistleri Dowling yöntemi ile patlatmadan doğurtarak çıkarttık (Resim 5) ve albendazol tedavisini $10 \mathrm{mg} / \mathrm{kg}$ günde $3 \mathrm{doz}$ halinde ve 6 ay boyunca uyguladık. Bu hastalarımızın takiplerinde nüks saptamadık.

Hastalarımızın birinde postoperatif erken dönemde subdural higroma (Resim 6), geç dönemde ise porensefalik kist gelişti. Subdural higroması takip sırasında gerilemediği ve hemipareziye neden olduğu için hastamıza subduro-peritoneal şant taktık. Ayrıca hastamızın porensefalik kistinde basınçlı jet akım saptadığımızdan (Resim 7) hastayı tekrar opere ettik ve valv etkisini ortadan kaldırmak üzere basınçlı porensefalik kisti subaraknoid mesafeye ağızlaştırdık. 


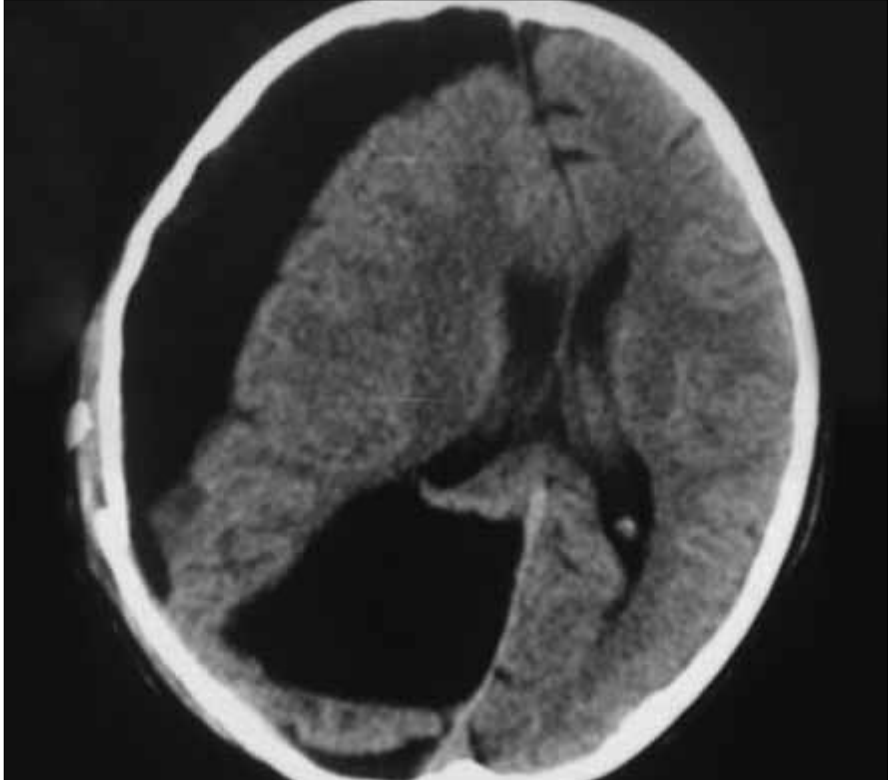

Resim 6. Bir olgumuzda ameliyat sonrasında gelişen subdural higroma beyin BT'sinde izlenmekte BT: bilgisayarlı tomografi

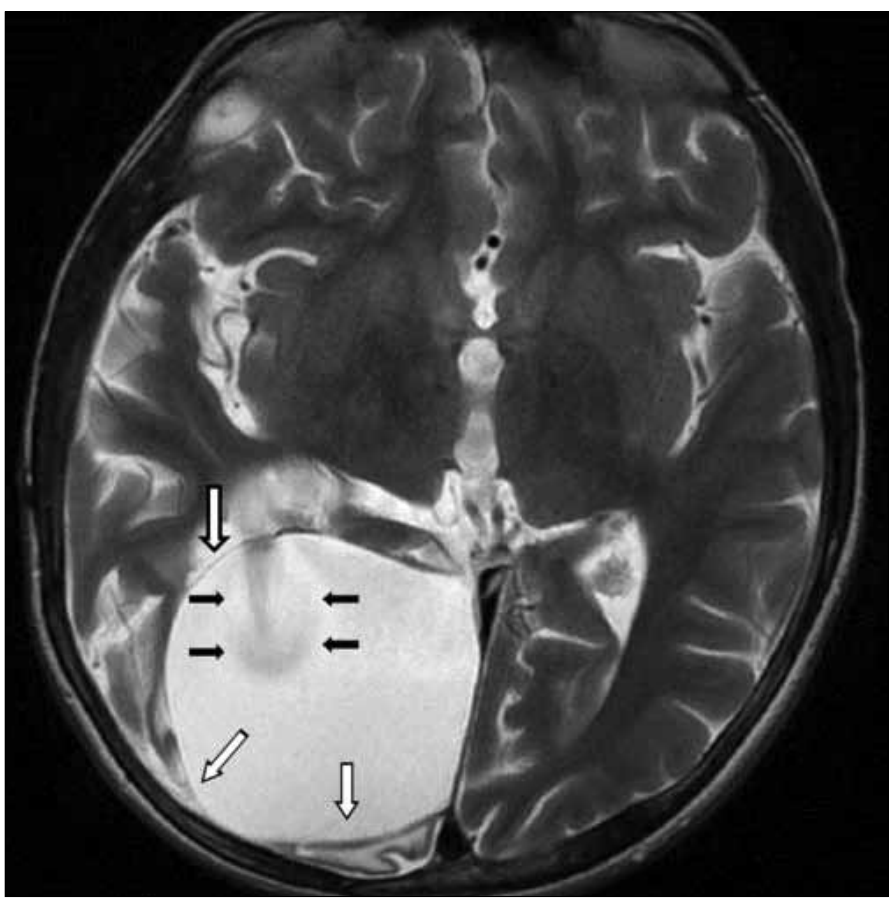

Resim 7. Bir hastamızda SKE çıkartılmasını takiben operasyon alanında basınçlı porensefalik kist geliştiği Kraniyal MRG'sinde görülmekte. Beyin omurilik sıvısının ventrikül içinden kist içine doğru jet akım (siyah oklar) ve kistik kavite çevresindeki ince dış membran görünümü (beyaz oklar) izlenmekte

SKE: serebral kistik ekinokokkoz

\section{SONUÇ}

SKE nadir rastlanan bir patolojidir. Supratentoryal bölge ve özellikle paryetal lob en sık yerleşim yeridir. Intraventriküler yerleşim oldukça nadirdir. Genellikle tektir ancak az da olsa multipl intakranial yerleşim mümkündür. Baş ağrısı ve kusma en sık başlangıç şikayetleridir. Ekstremitelerde güçsüzlük, görme bozukluğu, ataksi, epileptik nöbet, gaita inkontinansı gibi şikayetler kistin yerleşim yerine bağlı olarak görülebilir. Kistin büyümesi yavaş olduğundan semptomların gelişimi de yavaştır ve nörolojik defisitler genellikle intrakranial basınç artışına bağlı olarak geç dönemde görülmektedir. Papil ödemi tanı anında çoğunlukla bulunur. Literatürde çok nadir de olsa serebral herniasyon kliniği ile başvuran ve acil opere edilen olgular da mevcuttur. Tanı klinik, laboratuar ve görüntüleme yöntemleriyle konur. Seroloji yanında BT ve MRG tanıda oldukça önemlidir. Tedavisinde medikal ve cerrahi tedavi eş zamanlı olmalıdır. En küratif cerrahi yöntem kistin patlatılmadan Dowling yöntemiyle doğurtulması ve ameliyat boşluğunun hipertonik sodyum klorürle yıkanmasıdır.

Çıkar Çatışması: Yazarlar çıkar çatışması bildirmemişlerdir

Finansal Destek: Yazarlar bu çalışma için finansal destek almadıklarını beyan etmişlerdir.

\section{Hakem değerlendirmesi: Dış bağımsız.}

Yazar Katkıları: Fikir - Y.K.D.; Tasarım - Y.K.D., M.M.; Denetleme - Y.K.D., M.S.; Kaynaklar - Y.K.D., M.M.; Malzemeler - Y.K.D., M.M.; Veri toplanması ve/veya işlemesi - Y.K.D., M.M.; Analiz ve/ veya yorum - Y.K.D., M.M.; Literatür taraması - M.M., Y.K.D.; Yazıyı yazan - Y.K.D., M.M.; Eleştirel İnceleme - Y.K.D., M.S.; Diğer Y.K.D., M.M., M.S.

Conflict of Interest: No conflict of interest was declared by the authors.

Financial Disclosure: The authors declared that this study has received no financial support.

Peer-review: Externally peer-reviewed.

Author Contributions: Concept - Y.K.D.; Design - Y.K.D., M.M.; Supervision - Y.K.D., M.S.; Funding - Y.K.D., M.M.; Materials Y.K.D., M.M.; Data Collection and/or Processing - Y.K.D., M.M.; Analysis and/or Interpretation - Y.K.D., M.M.; Literature Review - M.M., Y.K.D.; Writing - Y.K.D., M.M.; Critical Review - Y.K.D., M.S.; Other - Y.K.D., M.M., M.S.

\section{KAYNAKLAR}

1. Guvenc G, Ozdemir N, Yıldırım L. Successful treatment of hydatid cyst into the lateral ventricle with Dowling's technique in an adult patient. J Neurol Sci (Turk) 2011; 28: 265-9.

2. Ozkan U, Kemaloglu MS, Selcuki M. Gigantic intracranial mass of hydatid cyst. Childs Nerv Syst 2001; 17: 623-5. [CrossRef]

3. Duishanbai S, Geng D, Liu C, Guo HR, Hao YJ, Liu B, et al. Research Group of Hydatid Diseases. Treatment of intracranial hydatid cysts. Chin Med J (Engl) 2011; 124: 2954-8.

4. Delibaş SB, Ozkoç S, Sahin S, Aksoy U, Akisü C. Evaluation of patients presenting with a suspicion of cystic echinococcosis to the serology laboratory of the Parasitology Department of Dokuz Eylül University Medical Faculty. Turkiye Parazitol Derg 2006; 30: 279-81.

5. Köktekir E, Erdem Y, Gökçek C, Karatay M, Yılmaz A, Bayar MA, Sümer S. Calcified intracranial hydatid cyst: case report. Turkiye Parazitol Derg 2011; 35: 220-3. [CrossRef] 
6. Tünger Ö. Epidemiology of cystic echinococcosis in the world. Turkiye Parazitol Derg 2013; 37: 47-52. [CrossRef]

7. Gupta S, Desai K, Goel A. Intracranial hydtid cyst: a report of five cases and review of literature. Neurol India 1999; 47: 214-7.

8. Izci Y, Tüzün Y, Seçer HI, Gönül E. Cerebral hydatid cysts: technique and pitfalls of surgical management. Neurosurg Focus 2008; 24: E15. [CrossRef]

9. Ersahin Y, Mutluer S, Guzelbag E. Intracranial hydatid cysts in children. Neurosurgery 1993; 33: 219-5. [CrossRef]

10. Guzel A, Tatli M, Maciaczyk J, Altinors N: Primary cerebral intraventricular hydatid cyst: a case report and review of the literature. J Child Neurol 2008; 23: 585-8. [CrossRef]

11. Aydin MD, Ozkan U, Altinörs N. Quadruplets hydatid cysts in brain ventricles: a case report. Clin Neurol Neurosurg 2002; 104: 300-2. [CrossRef]

12. Tascu A, Ciurea AV, Vapor I, Iliescu A, Brehar F. Giant asymptomatic intracranial hydatid cyst in a 3 years old child-case report. Romanian Neurosurg 2010; 17: 359-63.

13. Evliyaoglu C, Yuksel M, Gul B, Kaptanoglu E, Yaman M. Growth rate of multipl intracranial hydatid cysts assessed by CT from the time of embolisation. Neuroradiology 1998; 40: 387-9. [CrossRef]

14. Kemaloğlu S, Ozkan U, Bukte Y, Acar M, Ceviz A. Growth rate of cerebral hydatid cyst, with a review of the literature. Childs Nerv Sys 2001; 17: 743-5. [CrossRef]

15. Vaquero J, Jiménez C, Martinez R. Growth of hydatid cysts evaluated by $C T$ scanning after presumed cerebral hydatid embolism. Case report. J Neurosurg 1982;57(6):837-8.10- Kalelioglu M, Isik N, Sarier M, Köseoglu I, Unat MY, Kiroglu Y. Growth of multiple hydatid cysts evaluated by computed tomography. J Clin Neurosci 1998; 5: 215-7.
16. Kalelioglu M, Isik N, Sarier M, Köseoglu I, Unat MY, Kiroglu Y. Growth of multiple hydatid cysts evaluated by computed tomography. J Clin Neurosci 1998; 5: 215-7. [CrossRef]

17. Sierra J, Oviedo J, Berthier M, Leiguarda R. Growth rate of secondary hydatid cysts of the brain. Case report. J Neurosurg 1985; 62: 781-2. [CrossRef]

18. Paşaoğlu A, Orhon C, Akdemir H. Multiple primary hydatid cysts of the brain. Turk J Pediatr 1989; 31: 57-61.

19. Yurt A, Avci M, Selçuki M, Ozer F, Camlar M, Uçar K, et al. Multiple cerebral hydatid cysts. Report of a case with 24 pieces. Clin Neurol Neurosurg 2007; 109: 821-6. [CrossRef]

20. Cavuşoğlu H, Tuncer C, Ozdilmac A, Aydin Y. Multipl intracranial hydatid cysts in a boy. Turk Neurosurg 2009; 19: 203-7.

21. Bükte Y, Kemanoglu S, Nazaroglu H, Ozkan U, Ceviz A, Simsek M. Cerebral hydatid disease: CT and MR imaging findings. Swiss Med Wkly 2004; 134: 459-67.

22. Tuzun M, Altinörs N, Arda IS, Hekimoğlu B. Cerebral hydatid disease CT and MR findings. Clin Imaging 2002; 26: 353-7. [CrossRef]

23. Trivedi A, Shukla S, Singh K, Sharma V. Giant intracranial hydatid cyst. J Pediatr Neurosci 2007; 2: 72-4. [CrossRef]

24. Işıkay $S$, Kutluhan $Y$, Ölmez $A$. Two cases of rare cerebral hydatid cyst. Türkiye Parazitol Derg 2012; 36: 41-4. [CrossRef]

25. Onal C, Barlas O, Orakdögen M, Hepgül K, Izgi N, Unal F. Three unusual cases of intracranial hydatid cyst in the pediatric age group. Pediatr Neurosurg 1997; 26: 208-13. [CrossRef]

26. Sreedhar M. Disseminated hydatid disease. A case report with MR spectroscopic correlation. Ind J Radiol Imag 2006; 16: 771-4. [CrossRef]

27. Haliloglu M, Saatci I, Akhan O, Ozmen MN, Besim A. Spectrum of imaging findings in pediatric hydatid disease. AJR 1997; 169: 1627-31. [CrossRef] 